\title{
PENGARUH ORIENTASI PASAR TERHADAP PROSES BISNIS INTERNAL BALANCED SCORECARD PADA USAHA EKONOMI PRODUKTIF KELOMPOK USAHA BERSAMA (UEP - KUBe) DI BUKITTINGGI SUMATERA BARAT, INDONESIA
}

\section{THE EFFECT OF MARKET ORIENTATION ON INTERNAL BUSINESS PROCESS BALANCED SCORECARD IN PRODUCTIVE ECONOMIC BUSINESS - JOINT BUSINESS GROUP (PEB - JBG) IN BUKITTINGGI WEST SUMATERA, INDONESIA}

\author{
Irwan Ch' ${ }^{1)}$; Titiek Tjahja Andari ${ }^{2}$; Mas Nur Mukmin ${ }^{3)}$ \\ Program Studi Manajemen Fakultas Ekonomi Universitas Djuanda Bogor \\ e_mail : $\underline{\text { irwan.ch@unida.ac.id; titiek.tjahja@unida.ac.id; mas.nur.mukmin@unida.ac.id }}$
}

\begin{abstract}
This study aims to understand and analyze the influence of market orientation consisting of customer orientation and competitor orientation and coordination between functions on internal business processes - balance scorecard. The selection of respondents in this study was carried out using of a non-probability sampling of 110 managers of the Productive Economy Business - Joint Business Group (PEB-JBG) in the City of Bukittinggi, West Sumatra. The method used in this research is descriptive verification. The results showed that the manager of PEB-JBG understood that market orientation influenced internal business processes. The Market orientation, which consists of customer orientation and competitor orientation and coordination among functions, simultaneously influences internal business processes, while customer orientation and coordination between functions partially affect internal business processes. The competitor orientation is not significant in partially influencing internal business processes.
\end{abstract}

Keywords: The Market Orientation, Internal Business Processes, Productive Economic Business - Joint Business Groups

\begin{abstract}
ABSTRAK
Penelitian ini bertujuan untuk memahami dan menganalisis pengaruh orientasi pasar yang terdiri dari orientasi pelanggan dan orientasi pesaing serta koordinasi antar fungsi terhadap proses bisnis internal - balance scorecard. Pemilihan responden dalam penelitian ini dilakukan cara nonprobability sampling terhadap 110 pengelola Usaha Ekonomi Produktif - Kelompok Usaha Bersama (UEP-KUBe) di Kota Bukittinggi Sumatera Barat. Adapun metode yang digunakan dalam penelitian ini adalah descriptive verification. Hasil penelitian menunjukkan bahwa pengelola UEP-KUBe sangat memahami bahwa orientasi pasar berpengaruh terhadap proses bisnis internal. Orientasi pasar yang terdiri dari orientasi pelanggan dan orientasi pesaing serta koordinasi antar fungsi, secara bersama-sama (simultan) berpengaruh terhadap proses bisnis internal, sedangkan orientasi pelanggan dan koordinasi antar fungsi mempengaruhi proses bisnis internal secara parsial. Adapun orientasi pesaing tidak signifikan secara parsial mempengaruhi proses bisnis internal.
\end{abstract}

Kata Kunci : Orientasi Pasar, Proses Bisnis Internal, Usaha Ekonomi Produktif - Kelompok Usaha Bersama 


\section{PENDAHULUAN}

Usaha Mikro Kecil dan Menengah memiliki peran dalam perekonomian, termasuk lapangan kerja, terutama setelah krisis (finansial dan ekonomi) yang terjadi di Indonesia pada tahun 1997/1998. Oleh sebab itu, Usaha Mikro Kecil dan Menengah merupakan salah satu bagian penting sebagai penggerak dalam perekonomian Indonesia. Pada tahun 2017 telah menyumbangkan Rp7.740 triliun terhadap Produk Domestik Bruto (PDB) dan mempekerjakan lebih dari 116 juta orang dan 66.922.617 unit usaha atau 99,99\% dari jumlah pelaku bisnis di Indonesia (Badan Pusat Statistik, 2018).

Usaha Mikro Kecil dan Menengah di Indonesia telah menjadi bagian penting dari sistem perekonomian di Indonesia. Hal ini dikarenakan Usaha Mikro Kecil dan Menengah merupakan unit-unit usaha yang lebih banyak jumlahnya dibandingkan usaha industri berskala besar dan memiliki keunggulan dalam menyerap tenaga kerja lebih banyak dan juga mampu mempercepat proses pemerataan sebagai bagian dari pembangunan. "Berdasarkan kenyataan ini sudah selayaknya Usaha Mikro Kecil dan Menengah dilindungi dengan undang-undang dan peraturan yang terkait dalam kegiatan oprasional dan pengembanganya. Beberapa peraturan telah dikeluarkan oleh pemerintah untuk melindungi Usaha Mikro Kecil dan Menengah diantaranya Undang Undang Dasar 1945 merupakan pondasi dasar hukum di Indonesia Pasal 5 ayat(1), Pasal 20, Pasal 27 ayat (2), Pasal 33, Undang-undang Nomor 9 Tahun 1995, Ketetapan Majelis Permusyawaratan Rakyat Republik Indonesia Nomor XVI/MPR-RI/1998 tentang Politik Ekonomi dalam rangka Demokrasi Ekonomi, Usaha Mikro, Kecil, dan Menengah perlu diberdayakan sebagai bagian integral ekonomi rakyat yang mempunyai kedudukan, peran, dan potensi strategis untuk mewujudkan struktur perekonomian nasional yang makin seimbang, berkembang, dan berkeadilan, Peraturan Presiden Nomor 5 Tahun 2007 mengenai program Kredit Usaha Kecil bagi pembiayaan operasional Usaha Mikro Kecil dan Menengah, Undang-undang Nomor 20 Tahun 2008 tentang pemberdayaan Usaha Mikro Kecil dan Menengah, bagi perekonomian di Indonesia (Suci, 2017).

Darwanto, 2013 dalam Suci (2017) melakukan pengamatan terhadap pertumbuhan Usaha Mikro Kecil dan Menengah, dalam perekonomian di Indonesia yang merupakan bagian dari perekonomian, juga harus lebih meningkatkan daya saing dengan melakukan inovasi. Keunggulan bersaing berbasis inovasi dan kreativitas harus lebih diutamakan karena mempunyai daya tahan dan jangka waktu lebih panjang. Penelitian ini bertujuan merumuskan strategi kelembagaan dalam mendorong inovasi dan kreativitas pelaku Usaha Mikro Kecil dan Menengah.

Perusahaan yang berorientasi pasar akan melakukan lebih baik daripada yang lain. Orientasi pasar adalah salah satu faktor tidak berwujud, tetapi berdampak pada kinerja perusahaan (Krohmer, Workman, dan Homburg, 2003). Selain itu, Orientasi Pasar adalah budaya bisnis yang akan menciptakan kinerja yang unggul dengan menciptakan nilai bagi pelanggan (Slater dan Narver, 2000). Orientasi kewirausahaan dan orientasi pasar mempengaruhi kinerja Usaha Kecil dan Menengah di sektor manufaktur garmen di Sri Lanka, sebagaimana dikemukakan oleh Kumara et al. (2014). Penelitian ini dimaksudkan untuk menganalisis faktorfaktor utama untuk meningkatkan kinerja Usaha Kecil dan Menengah yang terlibat dalam pembuatan garmen. Hasil penelitian menunjukkan bahwa ada pengaruh orientasi pasar dan orientasi kewirausahaan dengan kinerja bisnis yang positif (Silviasih, Slamet, dan Iskandar, 2016). 


\section{MATERI}

Pengukuran suatu kinerja disesuaikan dengan tujuan analisis dan subyek penelitian. Pada umumnya, perusahaan cenderung fokus pada ukuran kinerja keuangan, seperti laba, aliran kas, dan nilai persediaan. Sebaliknya, perusahaan dalam lingkungan bisnis kontemporer menggunakan ukuran strategis yang bersifat non keuangan, seperti pangsa pasar, mutu produk, dan kepuasan pelanggan. Ukuran strategis yang bersifat keuangan dan non keuangan biasanya disebut faktor keberhasilan kritis (critical succes factor). Dalam mengembangkan ukuran critical success factor harus melibatkan studi secara hati-hati terhadap proses bisnis perusahaan (Hartini, 2013).

Kaplan dan Norton (1996) dalam Hartini, 2013 menjelaskan dimensi pengukuran kinerja perusahaan yang dikenal dengan balance scorecard. Balance scorecard merupakan sekelompok tolak ukur kinerja yang terintegrasi yang berasal dari strategi perusahaan. Pendekatan dalam balance scorecard menggunakan empat dasar perspektif, yaitu : (1) Perspektif Financial, (2) Perspektif Pelanggan, (3) Perspektif Proses Bisnis Internal, dan (4) Perspektif Permbelajaran dan Pertumbuhan. Dalam penelitian ini, penilaian kinerja difokuskan pada perspektif proses bisnis internal,

Dalam perspektif proses bisnis internal, manajer mengidentifikasi berbagai proses penting yang harus dikuasai perusahaan dengan baik. Kinerja proses bisnis internal tidak hanya memusatkan perhatian pada pemantauan dan perbaikan biaya dan mutu saja. Proses bisnis internal ini menekankan krakteristik biaya, mutu dan waktu. Terdapat hubungan kausal antara perspektif pembelajaran dan pertumbuhan dengan perspektif proses bisnis internal. Karyawan yang melakukan pembelajaran merupakan sumber ide baru yang terbaik untuk proses bisnis yang lebih baik. Pelanggan menilai barang dan jasa yang diterima dapat diandalkan dan tepat waktu.
Perusahaan dapat memuaskan pelanggan apabila mereka memiliki jumlah persediaan yang banyak untuk meyakinkan bahwa barang-barang tersedia di tangan. Tetapi biaya penanganan dan penyimpanan persediaan menjadi tinggi dan kemungkinan keusangan persediaan. Alternatif yang mungkin untuk menghindari persediaan yang berlebihan adalah membuat pemasok mengurangi throughput time. Throughput time adalah total waktu dari waktu pesanan diterima oleh perusahaan sampai dengan pelanggan menerima produk, memperpendek throughput time dapat berguna apabila pelanggan menginginkan (Hartini, 2013).

Orientasi pasar merupakan budaya organisasi yang mengarah pada pasar. komponen dalam orientasi pasar antara lain: orientasi pelanggan, orientasi pesaing dan koordinasi antar fungsi (Hooley et al. 2012). Starting point dari orientasi pasar adalah intelijen pasar yang digunakan untuk mengartikulasikan upaya-upaya dalam memahami bukan saja preferensi dan kebutuhan pasar yang terungkap, tetapi juga mencakup sebuah analisis mengenai bagaimana preferensi dan kebutuhan itu dipengaruhi oleh faktor-faktor eksogen seperti peraturan pemerintah, teknologi, pesaing, dan kekuatan-kekuatan lingkungan lainnya. Orientasi pasar fokus pada pemahaman keinginan dan kebutuhan pelanggan saat ini dan masa akan datang. Orientasi pasar dapat didefinisikan dengan lebih luas sebagai memperluas pemahaman tradisional dengan menggabungkan orientasi distribusi dan lingkungan. Orientasi pasar juga didefinisikan sebagai seperangkat kepercayaan (belief) dan sistem nilai (value) yang menempatkan kepentingan pelanggan diatas segala-galanya untuk mengembangkan perusahaan yang menguntungkan dalam jangka panjang. (Hartini, 2008).

Lebih lanjut Hartini

menguraikan komponen utama orientasi pasar yang banyak digunakan Industri kecil terdiri dari orientasi pelanggan, orientasi 
pesaing. Orientasi pelanggan adalah memahami target market agar mampu menciptakan nilai unggul secara terusmenerus. Skala pengukuran orientasi pelanggan yang dikembangkan Narver dan Slater terdiri dari komitmen pada pelanggan, menciptakan nilai pelanggan, memahami kebutuhan pelanggan, dan kepuasan pelanggan. Orientasi pesaing adalah memahami kekuatan dan kelemahan jangka pendek, kapabilitas jangka panjang, serta strategi saat ini dan mendatang dari pesaingpesaingnya. Analisis pesaing saat ini dan pesaing potensial juga penting untuk dicermati. Hal ini perlu agar perusahaan dapat terus menciptakan dan menyalurkan nilai unggul kepada pelanggannya. Orientasi pasar menjadi pondasi dalam banyak kegiatan pemasaran praktis. Orientasi pasar bukanlah tanggung jawab bagian pemasaran semata, tetapi merupakan tanggung jawab bersama seluruh karyawan. Perusahaan yang berorientasi pada pelanggan dituntut untuk mengembangkan proses dan program yang didorong oleh kebutuhan pelanggan dengan mengembangkan sistem informasi pasar yang kuat, sasaran dan segmentasi pasar yang jeli, serta merekrut karyawan terbaik di bidang tersebut. Orientasi pasar mempunyai konsekuensi internal dan eksternal terhadap organisasi. Konsekuensi internal dijelaskan dengan adanya dampak orientasi pasar, antara lain terhadap komitmen karyawan, esprit de corps dan kepuasan karyawan serta inovasi produk. Perusahaan yang orientasi pasar tinggi mengutamakan kualitas/kesesuaian produk atau jasa yang ditawarkan dengan harapan/ spesifikasi yang ditetapkan pelanggan. Dengan demikian, orientasi pasar mempunyai dampak positif terhadap kualitas produk, yang pada akhirnya berdampak pada keunggulan bersaing dan kinerja perusahaan (Hartini, 2013).

Orientasi pasar berdampak positif pada Return on Investment, market share dan kesuksesan produk baru (Matsuno., et al. 2002). Semakin tinggi orientasi pasar maka produk akan sesuai dengan perkembangan kebutuhan dan keinginan konsumen, dengan demikian produk baru yang ditawarkan akan banyak diterima konsumen yang pada akhirnya akan memperluas market share, dengan meningkatnya market share maka akan meningkat pula pendapatan perusahaan. Peningkatan pendapatan perusahaan ini akan berdampak pada peningkatan Return on investment. Orientasi pasar menjadi variable antecedent dari keunggulan bersaing, dan kinerja perusahaan. Semakin perusahaan berorientasi pada konsumen yaitu memperhatikan semua kebutuhan dan keinginan konsumen, memperhatikan strategi pemasaran dan segala aktivitas yang dilakukan pesaing, maka perusahaan tersebut akan mampu menciptakan produk/jasa yang dapat memuaskan kebutuhan konsumen dengan cara lebih baik dari pesaing, dengan demikian produk atau jasa yang ditawarkan akan lebih unggul dibandingkan pesaing. Keunggulan bersaing ini akan berdampak pada preferensi konsumen atas produk/jasa yang ditawarkan perusahaan, dengan demikian untuk menang dalam persaingan pasar global seperti sekarang ini, orientasi pasar merupakan faktor penting yang harus selalu dievaluasi dan ditingkatkan di perusahaan (Hartini, 2013).

Silvisih, Slamet, dan Iskandar (2010) telah mengumpulkan mengumpulkan sejumlah hasil penelitian yang menunjukkan bahwa orientasi pasar mempengaruhi kinerja bisnis, yaitu: Orientasi pasar memiliki dampak langsung pada kinerja Usaha Kecil dan Menengah (Kelson, 2012 ; Wilson et al, 2014). Selanjutnya Morgan, Vorhies dan Autry, (2009) menjelaskan bahwa orientasi pasar membantu perusahaan menetapkan strategi dan pendekatan untuk memahami pasar. Pendapat lain menunjukkan bahwa orientasi pasar memberikan pemahaman yang baik tentang bisnis dan lingkungannya, sehingga kebutuhan pelanggan akan terpenuhi dengan cara yang lebih baik (Pandanyi dan Grainer, 2005). 
Kinerja yang lebih baik dalam memahami pelanggan dan pesaing akan dimiliki oleh perusahaan yang berorientasi pasar (Greenley dan Lings, 2009). Orientasi pasar diterapkan untuk meningkatkan hubungan pelanggan, sehingga meningkatkan kinerja penjualan, pertumbuhan, pangsa pasar dan laba (Morgan dan Hunt, 1994 dalam Shehu dan Mahmood, 2014)." Selain itu, Orientasi pasar akan menunjukkan bahwa ada korelasi positif dan sangat signifikan antara orientasi pasar dan kinerja perusahaan (Richard, Beverly dan Michael, 2012).

Orientasi pasar memiliki efek langsung pada kinerja perusahaan tidak hanya pada hasil pemasaran, tetapi orientasi pasar telah menjadi elemen penting yang telah menjembatani penelitian antara pemasaran dan manajemen (Ketchen dan Hult, 2001). Pendapat lain mengatakan bahwa Orientasi pasar dapat meningkatkan kinerja perusahaan di pasar. Karakteristik perusahaan yang menerapkan Orientasi pasar akan dilihat dari seberapa banyak mereka memahami untuk memenuhi kebutuhan pelanggan saat ini dan masa depan dan menggunakan kemampuan mereka untuk menawarkan solusi yang lebih unggul dari pesaing (Slater dan Narver, 2000).

\section{METODE}

Variabel independen dalam penelitian ini adalah Orientasi pasar yang terdiri dari orientasi pelanggan dan orientasi pesaing serta koordinasi antar fungsi, sedangkan variabel dependen adalah kinerja dalam perspektif proses bisnis internal. Penelitian ini dilakukan di Kota Bukittinggi, Provinsi Sumatera Barat, Indonesia dengan metode pengumpulan data menggunakan kuesioner yang ditujukan untuk pelaku Usaha Ekonomi Produktif - Kelompok Usaha Bersama (UEP - KUBe).

Metode pemilihan sampel dilaksanakan dengan cara non-probability sampling, yang merupakan teknik yang tidak menggunakan prosedur pemilihan peluang, tetapi hanya didasarkan pada penilaian pribadi peneliti. (Malhorta, 2005). Judgment sampling adalah suatu bentuk convenience sampling yang berisi unsur-unsur populasi yang sengaja dipilih berdasarkan pendapat peneliti saja (Malhotra, 2005). Jumlah responden dalam penelitian ini adalah 110 dari Usaha Ekonomi Produktif - Kelompok Usaha Bersama (UEPKUBe) di Kota Bukittinggi, Provinsi Sumatera Barat, Indonesia.

Pertanyaan-pertanyaan dalam kuesioner menggunakan skala Likert adalah: (1) berarti mereka sangat tidak setuju atau tidak penting, (2) tidak setuju atau jarang, (3) ragu atau kadang-kadang, (4) setuju atau sering, (5) sangat setuju atau sangat sering. Selanjutnya, pengolahan data menggunakan Aplikasi Statistical Product and Service Solutions (SPSS IBM) Selain itu, data instrumen penelitian dilakukan beberapa tes, yaitu: uji validitas data, uji reliabilitas data, normalitas, autokorelasi dan uji lainnya yang relevan.

\section{HASIL DAN PEMBAHASAN}

Pelaku Usaha Ekonomi Produktif Kelompok Usaha Bersama (UEP-KUBe), secara umum mempunyai karakteristik dengan pelaku usaha perempuan 20,91\% dan sisanya yaitu mayoritas laki-laki sebanyak $79,09 \%$. Uusia antara 46 - 55 tahun sebanyak $41,82 \%$ dan usia 36 - 45 tahun sebanyak $39,09 \%$. Selain itu, pelaku usaha telah menikah $=93,64 \%$ dan durasi menjalankan Usaha Ekonomi Produktif - Kelompok Usaha Bersama (UEP-KUBe) adalah 5 hingga 7 tahun sebanyak 20,00\% dan 2 hingga 4 tahun sebanyak 34,55\% sehingga dapat dikatakan sudah cukup berpengalaman dalam melakukan aktivitasnya. Adapun yang telah memiliki izin usaha $63,64 \%$ dengan rata-rata jumlah pekerja $<5$ orang $(53,64 \%)$ dan antara 5-10 orang $42,73 \%$. Gambaran umum 
tersebut dapat dilihat lebih rinci sebagaimana tabel 1 dibawah ini.

Tabel 1

Karakterik Pengelola UEP KUBe

\begin{tabular}{|c|l|l|l|l|l|}
\hline No. & \multicolumn{2}{|c|}{ Karakteristik } & \multicolumn{2}{|c|}{$\begin{array}{c}\text { Ciri-Ciri Pengelola UEP-KUBe } \\
\text { (Dominan / Utama) }\end{array}$} & \multicolumn{2}{|c|}{ Persentase } \\
\hline 1 & Jenis Kelamin & Wanita & & $20,91 \%$ & \\
\hline 2 & Usia & $46-55$ thn & $36-45$ thn & $41,82 \%$ & $39,09 \%$ \\
\hline 3 & Pendidikan & Diploma & SMA/Sederajat & $10,91 \%$ & $78,18 \%$ \\
\hline 4 & Status Pernikahan & Menikah & & $93,64 \%$ & \\
\hline 5 & Lama Usaha & $5-7$ tahun & $2-4$ tahun & $20,00 \%$ & $34,55 \%$ \\
\hline 6 & ljin Usaha & $\begin{array}{l}\text { Memiliki ljin } \\
\text { Usaha }\end{array}$ & & $63,64 \%$ & \\
\hline 7 & Jumlah Tenaga Kerja & $5-10$ orang & $<5$ orang & $42,73 \%$ & $53,64 \%$ \\
\hline 8 & Jumlah Kekayaan & $<$ Rp.30 juta & 30 ; s/d 40 juta & $12,73 \%$ & $50,00 \%$ \\
\hline 9 & Omzet Penjualan/ bulan & $<$ Rp.10 juta & 10 ; s/d 50 juta & $38,18 \%$ & $43,64 \%$ \\
\hline
\end{tabular}

Tabel 2

Penilaian Pengelola UEP KUBe

\begin{tabular}{|c|c|c|c|c|}
\hline No. & Rewirausahaan & $\begin{array}{c}\text { Rata-Pata Pesilgias } \\
\text { Pengelda u日? } \\
\text { nuse }\end{array}$ & $\begin{array}{l}\text { Mayoritas rata- } \\
\text { Rata Pesilalan } \\
\text { Pengelola }\end{array}$ & Keterangan \\
\hline A & Orientasi Pasar & $\$ 14$ & $56,26 \%$ & Sanzat Setuju \\
\hline 1 & Orientasi Pelanggan & 4,56 & $68,79 \%$ & Sangat Setuju \\
\hline 2 & Orientasi Pesaing & 3,85 & $52,12 \%$ & Setuju \\
\hline 3 & Koordinasi Antar Fungsi & 4,01 & $4788 \%$ & Sangat Setuju \\
\hline
\end{tabular}

Kondisi pasar sangat dipahami pengaruhnya oleh pelaku usaha terhadap kondisi bisnis mereka yaitu orientasi pasar, orientasi pelanggan dan koordinasi antar fungsi dengan nilai rata-rata 4,41 (sangat setuju) dan merupakan mayoritas rata-rata penilaian pengelola usaha $56,26 \%$. Secara lebih terinci dapat dilihat pada tabel 2 tersebut diatas.

Pengujian yang dilakukan untuk menentukan kelayakan data yang akan digunakan, dilaksanakan dengan beberapa uji antara lain sebagaimana diuraikan dibawah ini.

Uji Validitas data dilakukan korelasi bivariat dari setiap skor indikator dengan skor total masing-masing indikator. Validitas setiap item ditunjukkan pada "Jumlah" dan ternyata semua item $\boldsymbol{r}$ hitung lebih besar dari $r$ tabel (nilai Pearson Correlation minimal adalah 0,1857). Hal ini ditandai dengan tanda $* *$ pada kolom “Jumlah", sehingga seluruh item kuesioner tersebut dinyatakan valid sebagaimana tabel 3 dibawah ini.

Tabel 3

Perhitungan Pearson Correlation (r-hitung)

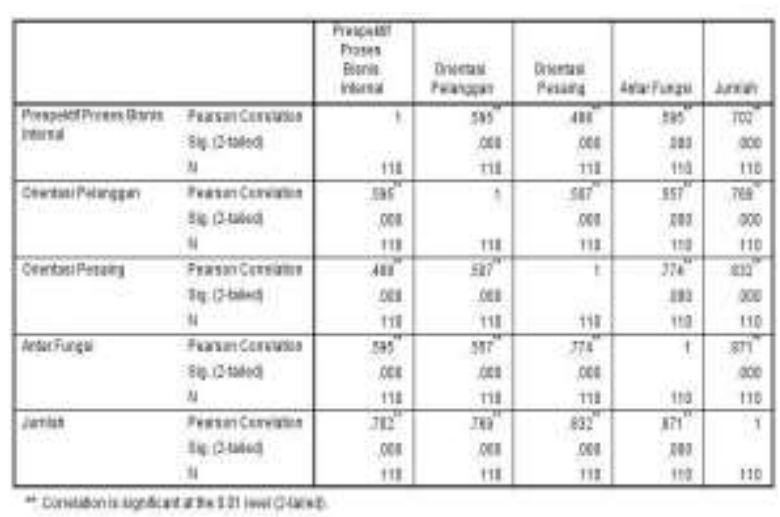

Uji Reliabilitas data diukur dari jawaban atas pertanyaan yang diajukan guna melihat konsistensi jawaban dari waktu ke waktu dengan hasil, sebagai berikut:

Tabel 4

Case Processing Summary

\begin{tabular}{|ll|r|r|} 
& & \multicolumn{1}{|c|}{ iv } & \multicolumn{1}{c|}{ >0 } \\
\hline Cases & Valid & 110 & 100.0 \\
& Excluded & \\
& Total & 0 & .0 \\
& Total & 110 & 100.0 \\
\hline
\end{tabular}

a. Listwise deletion based on all variables in the procedure.

Berdasarkan seluruh data yang telah dilakukan uji, ternyata 110 data $(100,00 \%)$ dinyatakan valid.

Tabel 5

Reliability Statistics

\begin{tabular}{|r|r|}
\hline $\begin{array}{c}\text { Cronbach's } \\
\text { Alpha }\end{array}$ & N of Items \\
\hline .843 & 4 \\
\hline
\end{tabular}

Berdasarkan uji tersebut diatas, tabel reliability statistics menunjukkan hasil uji reliabilitas dengan Cronbach's Alpha $=0,843$ dari 4 item variabel, sehingga dapat digunakan dalam proses selanjutnya. Jika nilai Cronbach's alpha lebih besar dari 0,60, 
data dapat dikatakan andal (Nunnally, 1967 dalam Ghozali, 2001).

Tabel 6

Item-Total Statistics

\begin{tabular}{|c|c|c|c|c|}
\hline & $\begin{array}{l}\text { Scate llaanif } \\
\text { Item Delsted }\end{array}$ & $\begin{array}{c}\text { Stale } \\
\text { Variance if } \\
\text { tem Deleted }\end{array}$ & $\begin{array}{l}\text { Comrected } \\
\text { Henr-Total } \\
\text { Conrelation }\end{array}$ & $\begin{array}{c}\text { Cronbach's } \\
\text { Alpha ifltem } \\
\text { Delated }\end{array}$ \\
\hline $\begin{array}{l}\text { Prespektif Proses Bisnis } \\
\text { internal }\end{array}$ & 124242 & 4.668 & 644 & 828 \\
\hline Crientasi Pelangyan & 11.4527 & 4.335 & 625 & 823 \\
\hline Crientasi Pesaing & 121648 & 3.563 & 718 & 786 \\
\hline Antar Fungsi & 120072 & 3.374 & 789 & .750 \\
\hline
\end{tabular}

Di dalam tabel item-total statistics dapat diketahui bahwa untuk masing-masing variabel nilai Conbrach's Alpha masih berada diatas 0,60 sehingga data masih sangat layak digunakan selanjutnya.

Uji Normalitas data dilakukan dalam bentuk Uji Kolmogorov-Smirnov diperoleh nilai signifikansi Asymp.Sig (2-tailed) sebesar 0,81 lebih besar dari 0,05 . Oleh karena itu sesuai dengan dasar pengambilan keputusan dalam uji normalitas dengan Kolmogorovsmirnov dapat disimpulkan bahwa data berdistribusi normal. Adapun rincian perhitungan sebagaimana dibawah ini.

Tabel 7

One-Sample Kolmogorov-Smirnov Test

\begin{tabular}{|ll|r|}
\hline & & $\begin{array}{r}\text { Unstandardiz } \\
\text { ed Residual }\end{array}$ \\
\hline $\mathrm{N}$ & Mean & 110 \\
Normal Parameters & & .0000000 \\
& Std. Deviation & .42358759 \\
Most Extreme Differences & Absolute & .080 \\
& Positive & .080 \\
& Negative & -.043 \\
Test Statistic & & .080 \\
Asymp. Sig. (2-tailed) & & $.081^{\circ}$ \\
\hline
\end{tabular}

a. Test distribution is Normal.

b. Calculated from data.

c. Lilliefors Significance Correction.

Uji Autokorelasi dilakukan dengan cara menghitung nilai Durbin-Watson (d) diperoleh nilai 1,868 lebih besar dari batas atas (du) yaitu 1,7455 dan kurang dari (4-du) yaitu: $\quad 4-1,745=2,2545$. Oleh sebab itu dapat disimpulkan bahwa tidak terdapat masalah atau gejala autokorelasi. Adapun rincian perhitungannya sebagaimana tabel 8 dibawah ini.

Tabel 8

Perhitungan Nilai Durbin-Watson (d)

\begin{tabular}{|c|c|c|c|c|c|}
\hline Model & $R$ & R Square & $\begin{array}{l}\text { Adjusted R } \\
\text { Square }\end{array}$ & $\begin{array}{l}\text { Std. Error of } \\
\text { the Estimate }\end{array}$ & $\begin{array}{l}\text { Durbin- } \\
\text { Watson }\end{array}$ \\
\hline 1 & $.674^{\mathrm{a}}$ & .454 & .439 & .42954 & 1.868 \\
\hline
\end{tabular}

Uji Multikolineritas dengan perhitungan Tolerance dan VIF dapat diketahui bahwa ketiga variabel independen tersebut nilai Tolerance-nya lebih besar dari 0,10 dan nilai VIF-nya lebih kecil dari 10,00. Dengan demikian dapat disimpulkan bahwa tidak terjadi gejala multikolinearitas. Adapun rincian perhitungannya sebagaimana tabel 9 dibawah ini.

Tabel 9

Collinearity Statistics (Tolerance dan VIF

\begin{tabular}{|c|c|c|c|c|c|c|c|c|}
\hline \multirow[b]{2}{*}{ Isyge] } & & \multicolumn{2}{|c|}{ 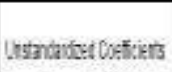 } & \multirow{2}{*}{$\begin{array}{l}\text { Santeried } \\
\text { Gefivats } \\
\text { Biala }\end{array}$} & \multirow[b]{2}{*}{$t$} & \multirow[b]{2}{*}{31} & \multicolumn{2}{|c|}{ Girentystifics } \\
\hline & & 8 & SwEx & & & & Tolenax: & If \\
\hline 1 & Constint? & $12 \%$ & 262 & & 4868 & $m$ & & \\
\hline & Cientaipelorygan & 294 & 867 & 32 & 4378 & (1) & .675 & 1.81 \\
\hline & Cistasipesain & . $n 1$ & (87) & - III & $-2 \mathrm{AH}$ & 92 & 393 & 2513 \\
\hline & Antriungs & 29 & 6075 & 342 & 320 & M2. & 35 & 274 \\
\hline
\end{tabular}

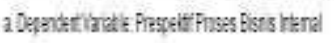

Tabel 10

Perhitungan Nilai Glesjer

\begin{tabular}{|c|c|c|c|c|c|c|}
\hline \multirow[b]{2}{*}{ Wostal } & & \multicolumn{2}{|c|}{ Unstandarafoed Cozficients } & \multirow{2}{*}{$\begin{array}{c}\begin{array}{c}\text { Standardized } \\
\text { Cuefciarts }\end{array} \\
\text { Betha }\end{array}$} & \multirow[b]{2}{*}{$t$} & \multirow[b]{2}{*}{$\mathrm{Sig}$} \\
\hline & & $B$ & Stiv. Entor & & & \\
\hline \multirow[t]{4}{*}{1} & (Constant) & 807 & .142 & & 5660 & .901 \\
\hline & Oriantasi Pelangagn & -025 & 93 & -074 & $-6 \subseteq 2$ & 499 \\
\hline & Orientasi Pesaing & 0105 & .941 & 197 & 1.400 & 164 \\
\hline & Intar Funģsi & -141 & 041 & -528 & -1.475 & .074 \\
\hline
\end{tabular}

Uji Heteroskedastisitas dilakukan dengan metode Glesjer, diperoleh nilai signifikansi untuk masing-masing variabel 
independen berturut-turut yaitu 0,49 dan 0,16 serta 0,07 yang berarti semuanya diatas 0,05 , maka dapat disimpulkan data yang akan digunakan tidak terjadi masalah heteroskedastisitas. Adapun rincian perhitungannya sebagaimana pada tabel 10 tersebut diatas.

Statistik Deskriptif digunakan untuk menentukan nilai rata-rata, median, minimum, maksimum, dan standar deviasi dalam penelitian. Statistik deskriptif termasuk frekuensi, rata-rata, dan standar deviasi, yang menyediakan informasi deskriptif tentang data (Sekaran dan Bougie, 2013), sebagaimana disajikan dalam tabel 11 tersebut diatas.

Tabel 11

Descriptive Statistics

\begin{tabular}{|c|c|c|c|c|c|c|c|}
\hline & \multirow{2}{*}{$\frac{\text { N1 }}{\text { Stristic }}$} & \multirow{2}{*}{\begin{tabular}{|l} 
Yrimum \\
Statiste \\
\end{tabular}} & \multirow{2}{*}{\begin{tabular}{|l} 
Vreinum \\
Statsici.
\end{tabular}} & \multicolumn{2}{|c|}{ Vean } & \multirow{2}{*}{\begin{tabular}{|l} 
Str. Deniation \\
Statsit:
\end{tabular}} & \multirow{2}{*}{$\begin{array}{l}\text { Variance } \\
\text { Staisi: }\end{array}$} \\
\hline & & & & Stetisti: & STI ETRr & & \\
\hline $\begin{array}{l}\text { Presplit Proes Bisnis } \\
\text { intmal }\end{array}$ & 110 & 163 & 475 & 35921 & 05427 & $5739 ?$ & 39 \\
\hline CrientasiPelanygan & 110 & 100 & 510 & $4563 \mathrm{i}$ & D7ug? & 74432 & 554 \\
\hline Crientasi Pesaing & 110 & 100 & 510 & 3.8515 & 02552 & 69602 & BCt \\
\hline Antar Fungsi & 110 & 100 & 510 & 4.0991 & .03547 & 50694 & 123 \\
\hline Varthlistwise! & 110 & & & & & & \\
\hline
\end{tabular}

Uji Signifikansi Simultan (Uji Statistik F) diperoleh nilai $F$ hitung sebesar 29,405 dengan probabilitas 0,000 . Sehubungan nilai probabilitas jauh lebih kecil dari 0,05, maka model dapat digunakan untuk memprediksi perspektif proses bisnis internal atau dapat disimpulkan bahwa koordinasi antar fungsi secara bersama-sama berpengaruh terhadap perspektif proses bisnis internal. Adapun output dari Aplikasi SPSS IBM ditunjukkan sebagaimana tabel 12 dibawah ini.

Tabel 12

Perhitungan Nilai Statistik F (Simultan)

\begin{tabular}{|c|c|c|c|c|c|c|}
\hline Nodel & & $\begin{array}{l}\text { Sum of } \\
\text { Squares }\end{array}$ & df & Nean Square & $F$ & Sig. \\
\hline \multirow[t]{3}{*}{1} & Regression & 16.276 & 3 & 5425 & 29.405 & $.000^{2}$ \\
\hline & Residual & 19.557 & 106 & 185 & & \\
\hline & Total & 35.834 & 109 & & & \\
\hline
\end{tabular}

a. Dependent Variable: Prespekfif Proses Bisnis intemal

b. Predicours (Constant, Antar Fungsi, Onientasi Pelanggan, Onientasi Pesang
Uji Signifikansi Parameter Individual (Uji Statistik t) dibutuhkan untuk menginter-pretasikan koefisien variabel bebas (independen) dan dapat menggunakan unstandardized coefficients maupun standardized coefficients. Berdasarkan kalkulasi yang dilakukan diperoleh hasil bahwa orientasi pelanggan dan koordinasi antar fungsi dengan nilai $t$ hitung masingmasing 4,378 dan 3,220 dengan probabilitas masing-masing-masingnya 0,000 dan 0,002 . Sehubungan dengan kedua variabel independen tersebut probabilitasnya jauh dibawah 0,05, maka dapat disimpulkan bahwa kedua variabel independent tersebut (signifikan) mempengaruhi variabel dependen (perspektif proses bisnis internal). Adapun variabel orientasi pesaing dengan probabilitas 0,992 atau jauh diatas 0,05 maka dapat disimpulkan bahwa variabel tersebut tidak signifikan mempengaruhi variabel dependen (perspektif proses bisnis internal). Adapun output dari Aplikasi SPSS IBM ditunjukkan sebagaimana tabel 13 dibawah ini.

Tabel 13

Perhitungan Nilai Statistik t (Individual)

\begin{tabular}{|c|c|c|c|c|c|c|}
\hline \multirow[b]{2}{*}{ Nodal } & & \multicolumn{2}{|c|}{ Unstantardzad Coeficients } & \multirow{2}{*}{$\frac{\text { Cosficients }}{\text { Deta }}$} & \multirow[b]{2}{*}{1} & \multirow[b]{2}{*}{59} \\
\hline & & $B$ & Stit Error & & & \\
\hline \multirow[t]{4}{*}{1} & (Constant) & 1.282 & .282 & & 4898 & 900 \\
\hline & Oriartasi Pelanggan & 294 & 167 & 32 & 4378 & 000 \\
\hline & Oniantasi Pesaing & -001 & 073 & -001 & -010 & 992 \\
\hline & Inter Fungsi & 242 & .075 & 32 & 3220 & 000 \\
\hline
\end{tabular}

a. Dapendart Variakla: Prespabif Poses Eisnis intemal

\section{KESIMPULAN DAN IMPLIKASI}

Berdasarkan uraian dalam pembahasan tersebut diatas, dapat disimpulkan sebagai berikut:

a. Pengelola Usaha Ekonomi Produktif Kelompok Usaha Bersama (UEPKUBe) sangat memahami pengaruh kondisi bisnis dari orientasi pasar, yang terdiri dari orientasi pasar, orientasi pelanggan dan koordinasi antar fungsi. Hal ini sejalan dengan pendapat 
Greenley dan Lings, 2009 bahwa perusahaan yang berorientasi pasar, secara umum akan memiliki kinerja yang lebih baik dalam memahami pelanggan dan pesaing.

b. Orientasi pasar yang terdiri dari orientasi pelanggan dan orientasi pesaing serta koordinasi antar fungsi, secara bersama-sama berpengaruh terhadap proses bisnis internal - balance scorecard. Slater dan Narver, 2000 dalam Silviasih et.al, menyatakan bahwa karakteristik utama perusahaan yang menerapkan prinsip-prinsip orientasi pasar dapat diamati dari sejauh mana pemahaman mereka untuk memenuhi kebutuhan pelanggan saat ini dan masa depan serta memberikan solusi untuk mengatasi kebutuhan pelanggan yang lebih baik dari pesaing.

c. Variabel orientasi pelanggan dan koordinasi antar fungsi mempengaruhi variabel dependen (perspektif proses bisnis internal) secara parsial, sedangkan orientasi pesaing tidak signifikan secara parsial mempengaruhi proses bisnis internal pengelola Usaha Ekonomi Produktif Kelompok Usaha Ekonomi Bersama (UEP-KUBe).

Adapun saran yang dapat dikemukan dari hasil kajian ini antara lain:

a. Walaupun Pengelola Usaha Ekonomi Produktif - Kelompok Usaha Bersama (UEP-KUBe) telah memahami dengan baik pengaruh kondisi bisnis dari orientasi pasar. Untuk itu, diharapkan mengubah pandangan mereka tentang fungsi pemasaran yang lebih luas dalam menjalankan bisnis, sehingga dapat terus tumbuh dan berkembang.

b. Bagi penelitian selanjutnya, agar dapat dikembangkan lebih luas dalam pengukuran kinerja balance scorecard pada aspek lainnya, seperti: perspektif financial, perspektif pelanggan dan perspektif pembelajaran dan pertumbuhan.

\section{DAFTAR PUSTAKA}

Greenley, G.E and Lings, I.N. 2009. "The Impact of Internal and External Market Orientations on Firm Performance. Journal of Strategic Management (Taylor \& Francis Online) 17 (1). Accessed June 29, 2019.

doi:https://doi.org/10.1080/09652540 802619251.

Hartini, S. (2008). The Effect of Market Orientation toward Firm's Innovation, Product Quality, Competitive Advantage and Firm's Performance of Small. Proceeding International Conference Business Research.

Hartini, S. 2012. Peran Inovasi: Pengembangan Kualitas Produk dan Kinerja Bisnis. Jurnal Manajemen dan Kewirausahaan 14(1): 83-89

Hartini, Sri. 2013. "Hubungan Orientasi Pasar, Strategi Bersaing, Kewirausahaan Korporasi dan Kinerja Perusahaan." Ekuitas: Jurnal Ekonomi dan Keuangan (Sekolah Tinggi Ilmu Ekonomi Indonesia (STIESIA) Surabaya) 17 (1): 39 - 53. Accessed Mei 16, 2020. doi:https://ejournal.stiesia. ac.id/ekuitas/article/view/257/242.

Hooley, G. N. (2012). Marketing Strategy and Competitive Positioning. England: FT Prentice Hall.

Kaplan, R. dan D. Norton. 1996. Balance Scorecard, Boston: Harvard Business Press. Boston. 
Kelson, A.K., 2002. "A Quantitative Study of Market Orientation and Organizational Performance of Listed Companies: Evidence Form Grana." Journal of Management and Marketing Research 5 (7).

Ketchen, D.J, and Hult, G.T.M., 2001. "Does Market Orientation Matter? : A Test of the Relationship Between Positional Advantage and Performance." Strategic Management Journal 22 (9).

Krohmer, H., Workman, J.P, Homburg, C., 2003. "A Strategy Implementation Perspective of Market Orientation." Journal of Business Research.

Kumara, P.A.P.S., Wijesekara, W.A.D.S., and Gunawardana, T.S.L.W. 2014. "Impact of Market Orientation and Entrepreneurial Orientation on Performance: A Study of Small and Medium Scale Garment Manufacturers in Sri Lanka." The 3rd International Conference on Management and Economics. 373 - 386.

Shehu, A.M and Mahmood, R, 2014. "The Relationship Between Market Orientation and Business Performance of Nigerian S.M.E.s: The Role of Organizational Culture." International Journal of Business and Social Science 5 (9).

Matsuno K., J. T. (2002). The Effect of Proclivity and Market Orientation on Business Performance. Journal of Marketing, 18-32.

Malhotra. 2005. Riset Pemasaran. 4. Vol. 1. Jakarta: Indeks Kelompok Gramedia.
Pandanyi, P, and Grainer, B. 2005. "The Relationship Between MarketOriented Activities and MarketOriented Culture: Implications for the Development of Market Orientation in Nonprofit Service Organizations." Journal of Business Research 58.

Richard, C.B, Beverly, K.B., and Michael, A.J. 2012. "Customer Orientation and Performance in Small Firms: Examining Influence of Risk Taking, Innovativeness and Opportunity Focus." Journal of Small Business Management 50 (3).

Silviasih, Slamet, Franky dan Iskandar, Denny. 2016. "Pengaruh Orientasi Pasar dan Orientasi Kewirausahaan terhadap Kinerja Usaha pada Pemilik UKM Sektor Manufaktur Garmen di Tanah Abang Jakarta Pusat." Jurnal Ilmiah Manajemen Bisnis (Fakultas Ekonomi- Universitas Kristen Krida Wacana). Accessed Mart 14, 2019. https://media.neliti.com/media/public ations/ 98664-ID-pengaruh-orientasipasar-dan-orientasi-k.pdf.

Slater, S.F., and Narver, J.C. 2000. "The Positive Effect of a Market Orientation on Business Profitability: a Balanced Replication." Journal of Business Research 48 (1).

Suci, Y. R. (2017, Januari). Perkembangan UMKM (Usaha Mikro Kecil Menengah) di Indonesia. Jurnal Ilmiah Cano Ekonomos, 6(1). Retrieved Mei 17, 2020, from http://ejournal.upp.ac.id/index.php/Cano/article/ view/1239/pdf_44

Wilson, T.D., Aronson., A., Akert, R.M., 2005. Social Psychology. 5th. New York: Prentice-Hall, Inc. 